\title{
Expression of intestinal trefoil factor mRNA is downregulated during progression of colorectal carcinomas
}

\author{
Hirofumi Uchino, Hiroaki Kataoka, Hiroshi Itoh, Masashi Koono
}

\begin{abstract}
Aims-Intestinal trefoil factor is a mucosa associated trefoil peptide expressed predominantly in the goblet cells of the small and large intestine. The aim of this work was to investigate the expression of the intestinal trefoil factor gene in human colorectal cancers.

Methods-The expression of intestinal trefoil factor mRNA was examined by northern blot analysis in 27 cases of surgically resected primary colorectal carcinoma of various stages.

Results-Although intestinal trefoil factor mRNA was expressed consistently in the tumours, the levels of expression varied considerably among the cases examined. The levels of expression were low in advanced stage tumours (Dukes's B, C, and D) compared with early stage tumours (Dukes's A) ( $\mathbf{p}<0.05)$. In addition, there was a tendency towards a positive correlation, albeit not well defined, between the amounts of intestinal trefoil factor mRNA and the histological differentiation of tumours.

Conclusions-Intestinal trefoil factor mRNA was expressed consistently in the cases of colorectal carcinoma studied and expression was inversely associated with tumour progression.

(7 Clin Pathol 1997;50:932-934)
\end{abstract}

Keywords: intestinal trefoil factor; colon carcinoma; mRNA expression

Intestinal trefoil factor is a small peptide bearing the unique motif of intrachain disulphide bonds characteristic of the trefoil family. This molecule is localised primarily within goblet cells in the small and large bowel. ${ }^{1-3}$ The pattern of intestinal trefoil factor expression is altered at sites of ulceration in the intestinal tract, ${ }^{3-5}$ suggesting that intestinal trefoil factor protects against ulcerative damage or has an important role in regeneration of the damaged mucosa. Indeed, targeting disruption of the intestinal trefoil factor gene in mice resulted in impairment of mucosal healing and epithelial regeneration. ${ }^{6}$ Experimental evidence suggests that intestinal trefoil factor is a motogen, capable of promoting the migration of epithelial cells. $^{7}$ To date, three human trefoil peptides have been described: pS2, spasmolytic polypeptide, and intestinal trefoil factor. Although little is known about the functional roles of these peptides in cancer, $\mathrm{pS} 2$ was identified as an oestrogen induced gene in a human breast carcinoma cell line, MCF-7, and has been reported to be expressed by various solid tumours such as carcinomas of the breast, stomach, pancreas, biliary tract, and colorectum. ${ }^{8}$ Recently, the presence of immunoreactive intestinal trefoil factor peptides was reported not only in normal colonic mucosa but also in colonic adenomas and carcinomas, and the amounts correlated with the degree of histological differentiation of the neoplastic tissues. ${ }^{9}$ However, the immunodetection may detect absorbed intestinal trefoil factor in addition to synthesised factor. For instance, immunostaining studies indicate that intestinal trefoil factor is present in goblet cells and absorptive enterocytes in the small and large intestine, ${ }^{2}$ whereas in situ hybridisation revealed that intestinal trefoil factor mRNA is abundant in goblet cells only. ${ }^{2}$ The aim of this study was to examine the presence of intestinal trefoil factor mRNA in colorectal carcinoma and to compare its level of expression with that found in the corresponding normal mucosal tissue. We report here that intestinal trefoil factor mRNA is expressed consistently in colorectal carcinoma, and that the level of expression of mRNA may be inversely related to the disease progression.

\section{Methods}

All tissue was received freshly from the operating room. The cases analysed were 27 primary colorectal carcinomas. In each case, tissue samples were taken from the primary tumour tissue and corresponding normal mucosal tissue. Total cellular RNA was extracted from the tissue samples using Trizol reagent (Gibco BRL, Gaithersburg, Maryland, USA). The extracted total RNA $(30 \mu \mathrm{g})$ was electrophoresed through a formaldehyde containing $1 \%$ agarose gel. The products of electrophoresis were transferred on to a Hybond $\mathrm{N}+$ nylon membrane (Amersham, Buckinghamshire, UK) and the RNA was UV crosslinked on to the membrane. Hybridisation was performed in a mixed solution of $50 \%$ formamide, $5 \times$ Denhardt's solution, $25 \mathrm{mM}$ phosphate buffer (pH 6.5), $0.1 \%$ sodium dodecyl sulphate (SDS), $100 \mu \mathrm{g} / \mathrm{ml}$ of sonicated and heat denatured salmon sperm DNA, and $5 \times$ standard saline citrate (SSC) at $42^{\circ} \mathrm{C}$ for 16 hours. The blots were washed as follows: three times in $1 \times$ SSC containing $0.1 \%$ SDS for 10 minutes at room temperature, followed by three times 
Table 1 Patient, pathological, and laboratory data

\begin{tabular}{|c|c|c|c|c|c|c|c|c|c|}
\hline \multicolumn{3}{|c|}{ Patient data } & \multicolumn{4}{|c|}{ Pathological findings } & \multicolumn{3}{|c|}{ ITF $m R N A$ level } \\
\hline Case & Age & Sex & Differentiation & $T N M$ & Stage & Dukes's & Tumour & Normal & $T: N$ \\
\hline 1 & 77 & $\mathbf{M}$ & Well & T3, N0, M0 & II & B & 0.024 & 0.047 & 0.502 \\
\hline 2 & 54 & $\mathbf{M}$ & Well & $\mathrm{T} 2, \mathrm{~N} 0, \mathrm{M} 0$ & I & A & 0.366 & 0.067 & 5.466 \\
\hline 3 & 73 & $\mathrm{~F}$ & Well & $\mathrm{T} 1, \mathrm{~N} 0, \mathrm{M} 0$ & I & A & 0.099 & 0.014 & 7.090 \\
\hline 4 & 89 & $\mathbf{M}$ & Well & T4, N0, M0 & II & B & 0.046 & 0.084 & 0.547 \\
\hline 5 & 71 & $\mathbf{M}$ & Well & T2, No, M0 & I & A & 0.031 & 0.049 & 0.648 \\
\hline 6 & 77 & M & Well & $\mathrm{T} 3, \mathrm{NO}, \mathrm{M} 0$ & II & B & 0.032 & 0.067 & 0.474 \\
\hline 7 & 53 & $\mathbf{M}$ & Well & $\mathrm{T} 2, \mathrm{~N} 1, \mathrm{M} 0$ & III & $\mathrm{C}$ & 0.009 & 0.030 & 0.294 \\
\hline 8 & 44 & $\mathrm{~F}$ & Well & T3, N0, M0 & II & B & 0.034 & 0.032 & 1.053 \\
\hline 9 & 72 & $\mathrm{~F}$ & Well & $\mathrm{T} 1, \mathrm{~N} 0, \mathrm{M} 0$ & I & A & 0.037 & 0.077 & 0.482 \\
\hline 10 & 65 & $\mathrm{~F}$ & Well & $\mathbf{x}$ & $\mathbf{x}$ & $\mathbf{x}$ & 0.038 & 0.023 & 1.645 \\
\hline 11 & 67 & $\mathbf{M}$ & Moderate & T2, N0, M0 & I & A & 0.084 & 0.031 & 2.692 \\
\hline 12 & 62 & $\mathrm{~F}$ & Moderate & $\mathrm{T} 3, \mathrm{~N} 2, \mathrm{M} 0$ & III & $\mathrm{C}$ & 0.024 & 0.058 & 0.418 \\
\hline 13 & 59 & $\mathrm{~F}$ & Moderate & $\mathrm{T} 2, \mathrm{~N} 0, \mathrm{M} 0$ & I & A & 0.089 & 0.047 & 1.916 \\
\hline 14 & 71 & $M$ & Moderate & $\mathrm{T} 3, \mathrm{~N} 1, \mathrm{M} 0$ & III & $\mathrm{C}$ & 0.105 & 0.032 & 3.263 \\
\hline 15 & 66 & $\mathbf{M}$ & Moderate & T4, N0, M0 & II & B & 0.060 & 0.051 & 1.166 \\
\hline 16 & 77 & $\mathrm{~F}$ & Moderate & $\mathrm{T} 2, \mathrm{~N} 0, \mathrm{M} 0$ & I & A & 0.035 & 0.075 & 0.468 \\
\hline 17 & 65 & $\mathrm{~F}$ & Moderate & $\mathrm{T} 3, \mathrm{~N} 1, \mathrm{M} 0$ & III & C & 0.090 & 0.026 & 3.427 \\
\hline 18 & 49 & $M$ & Moderate & T3, N0, M0 & II & B & 0.060 & 0.075 & 0.803 \\
\hline 19 & 71 & $\mathrm{~F}$ & Moderate & T3, N0, M0 & II & B & 0.014 & 0.043 & 0.326 \\
\hline 20 & 74 & $\mathrm{M}$ & Moderate & $\mathrm{T} 4, \mathrm{Nx}, \mathrm{M} 0$ & $\geqslant$ II & $\geqslant B$ & 0.007 & 0.119 & 0.062 \\
\hline 21 & 87 & $\mathbf{M}$ & Moderate & $\mathrm{T} 2, \mathrm{~N} 0, \mathrm{M} 0$ & I & A & 0.012 & 0.031 & 0.396 \\
\hline 22 & 69 & $\mathbf{M}$ & Moderate & $\mathrm{T} 4, \mathrm{~N} 3, \mathrm{M} 1$ & IV & $\mathrm{D}$ & 0.008 & 0.038 & 0.198 \\
\hline 23 & 74 & $\mathrm{~F}$ & Moderate & $\mathrm{T} 3, \mathrm{~N} 3, \mathrm{M} 0$ & III & $\mathrm{C}$ & 0.023 & 0.035 & 0.655 \\
\hline 24 & 67 & $\mathbf{M}$ & Moderate & $\mathrm{T} 4, \mathrm{~N} 1, \mathrm{M} 0$ & III & $\mathrm{C}$ & 0.023 & 0.046 & 0.489 \\
\hline 25 & 86 & $\mathrm{M}$ & Poor & $\mathrm{T} 4, \mathrm{~N} 0, \mathrm{M} 0$ & II & B & 0.016 & 0.080 & 0.196 \\
\hline 26 & 63 & $\mathbf{M}$ & Poor & $\mathrm{T} 3, \mathrm{~N} 3, \mathrm{M} 1$ & IV & $\mathrm{D}$ & 0.016 & 0.051 & 0.312 \\
\hline 27 & 43 & $M$ & Poor & $\mathrm{T} 2, \mathrm{~N} 0, \mathrm{M} 0$ & I & A & 0.044 & 0.043 & 1.035 \\
\hline
\end{tabular}

ITF mRNA concentrations are normalised by GAPDH as described in Methods.

ITF, intestinal trefoil factor; $T: N$, ratio of the signal in tumour to normal tissue.

$\mathrm{x}$, data not available.

in the same solution for 20 minutes at $65^{\circ} \mathrm{C}$. The membranes were autoradiographed with Kodak XR-5 film at $-80^{\circ} \mathrm{C}$ for either six hours or 18 hours. The intestinal trefoil factor cDNA (261 base pairs) corresponding to bases 22-282 of the human intestinal trefoil factor sequence $^{3}$ was synthesised by reverse transcriptase-polymerase chain reaction (RTPCR), subcloned into pCR II vector (Invitrogen, San Diego, California, USA), sequenced, and used as a probe. For internal control of loading, the blots were subsequently hybridised to the glyceraldehyde-3-phosphate dehydrogenase (GAPDH) probe (CLONTECH, Palo Alto, California, USA). The probes were radiolabelled by random priming with ${ }^{32} \mathrm{P}$-CTP. For quantification of the northern blot, the radioactivities of the mRNA signals for intesti- nal trefoil factor were measured directly by a Bioimaging Analyser, FUJIX BAS2000 system (Fuji Photo Film, Tokyo, Japan), and normalised by division through those of the corresponding GAPDH mRNA signals. Finally, a ratio of the intestinal trefoil factor signal in the tumour to that of the corresponding normal mucosal tissue $(\mathrm{T}: \mathrm{N})$ was calculated.

The pathological findings of all tissues examined were assessed independently by two pathologists. Diagnoses and terminology were according to those of the Histological Typing of Intestinal Tumours, World Health Organization. Sections taken adjacent to the tissue used for RNA extraction were assessed for the degree of histological differentiation.

Statistical parameters were ascertained with the Statview 4.02 program (Abacus Concepts,

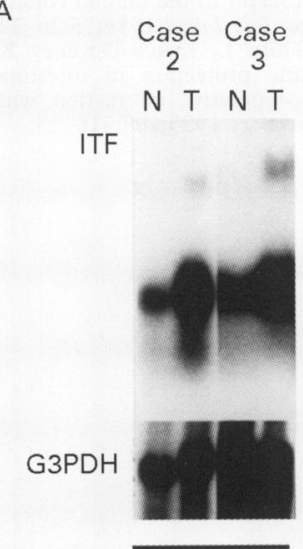

Histology
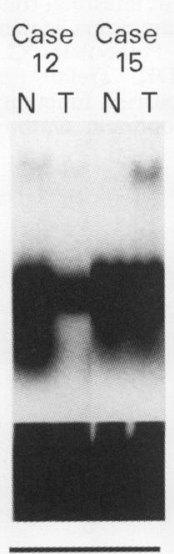

M
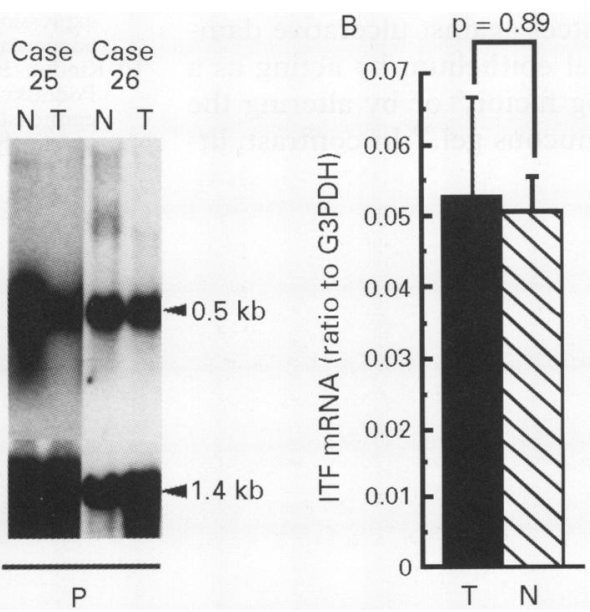
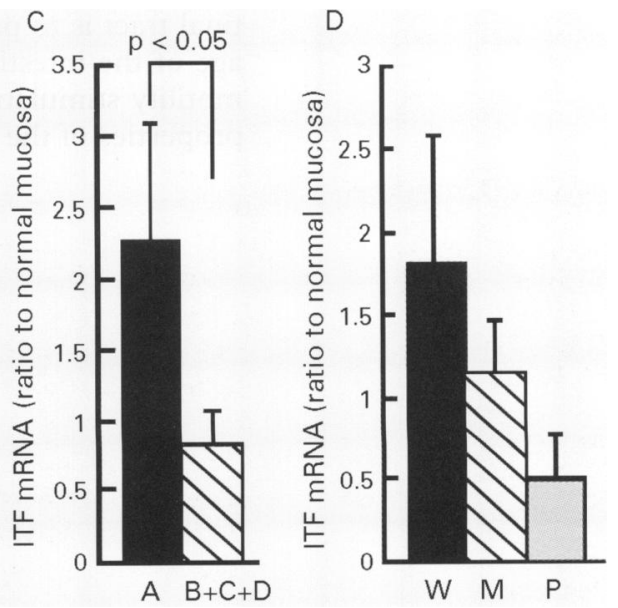

Figure 1 (A) Representative cases of northern blot for intestinal trefoil factor $m R N A$ expression. (B) No difference was detected in expression of intestinal trefoil factor $m R N A$ between tumours and normal mucosa. (C) Relation between intestinal trefoil factor $m R N A$ expression and tumour stage or (D) histological differentiation of colorectal carcinomas. (C) Dukes's $B, C$, and D stage tumours $(n=17)$ expressed less intestinal trefoil factor mRNA than stage A tumours $(n=9)$. (D) There may be a tendency towards a positive correlation between the expression of intestinal trefoil factor mRNA and the degree of histological differentiation. W, well differentiated $(n=10) ; M$, moderately differentiated $(n=14) ; P$, poorly differentiated $(n=3)$ adenocarcinoma. 
Inc, Berkeley, California, USA) and the results were expressed as the mean (SE). The data were tested for normality and then statistical significance was determined using a paired Student's $t$ test between the tumour and the corresponding normal mucosa and an unpaired Student's $t$ test between Dukes's stages. Also, the non-parametric test (Kruskal-Wallis test) was used for analysis between differentiation. Significance was set at $\mathrm{p}<0.05$.

\section{Results}

As shown in fig $1 \mathrm{~A}$, northern blot analysis revealed that all tumour tissues examined and the corresponding normal tissue expressed intestinal trefoil factor mRNA. There was no difference in intestinal trefoil factor mRNA expression between tumours and normal mucosa (fig 1A). Thus, the expression of intestinal trefoil factor mRNA is highly conserved in the colorectal carcinoma. A single mRNA species for intestinal trefoil factor of molecular size $\sim 0.5 \mathrm{~kb}$ was detectable in all cases. The clinicopathological data of the analysed cases and amount of intestinal trefoil factor mRNA of the tumour, expressed as $\mathrm{T}: \mathrm{N}$ value, are summarised in table 1 . Advanced stage tumours (Dukes's B, C, and D) expressed less intestinal trefoil factor mRNA than early stage tumours (Dukes's A), and the difference was statistically significant $(p<0.05)$ (fig $1 B)$. In addition, there was a tendency towards a positive correlation between intestinal trefoil factor mRNA level and the degree of histological differentiation of the tumours, although the results were not statistically significant (fig 1C).

\section{Discussion}

Intestinal trefoil factor is one of the most recently described members of the trefoil peptides, a family of peptides expressed abundantly in gastrointestinal mucous cells. Immunohistochemical studies indicate that intestinal trefoil factor is present in goblet cells and absorptive enterocytes in the intestine, whereas its mRNA is abundant in goblet cells only. ${ }^{2}$ Several lines of evidence have suggested that the function of this molecule in the gastrointestinal tract is to protect against ulcerative damage of the intestinal epithelium by acting as a motility stimulating factor, ${ }^{6}$ or by altering the properties of the mucous gel. ${ }^{10}$ In contrast, lit- tle is known about the expression and biological significance of intestinal trefoil factor in tumours. Recently, Taupin et al reported the presence of immunoreactive intestinal trefoil factor proteins in the colonic adenoma carcinoma sequence and showed that levels of immunoreactive intestinal trefoil factor in well or moderately well differentiated tumours were higher than those in poorly differentiated tumours. ${ }^{9}$ In the present study, we confirmed that intestinal trefoil factor mRNA is, in fact, expressed in colorectal carcinomas as well as in normal mucosa, and the levels of mRNA were inversely associated with the progression of the tumours. Therefore, our findings are in accordance with those of Taupin et al. ${ }^{9}$ As mentioned by Taupin $e t a l,{ }^{9}$ the detection of the intestinal trefoil factor peptide and/or mRNA may have diagnostic value for an intestinal origin in metastatic adenocarcinoma in which the primary site is unknown.

The authors thank Dr R Sekiya, T Shimayama and Y Takechi for providing specimens. This work was supported in part by a grant from the Tokyo Biochemical Research Foundation, Japan.

1 Suemori S, Lynch-Devaney K, Podolsky DK. Identification Suemori S, Lynch-Devaney K, Podolsky DK. Identification and characterization of rat intestinal trefoil factor: Tissueand cell-specific member of the

2 Podolsky DK, Lynch-Devaney K, Stow JL, Oates P, Murgue $\mathrm{B}$, DeBeaumont $\mathrm{M}$, et al. Identification of human intestinal trefoil factor. Goblet cell-specific expression of a peptide targeted for apical secretion. F Biol Chem 1993;268:6694 702 .

3 Hauser F, Poulsom R, Chinery R, Rogers LE, Hanby AM, Wright NA, et al. hP1.B, a human P-domain peptide homologous with rat intestinal trefoil factor, is expressed also in the ulcer-associated cell lineage and the uterus. Proc Natl Acad Sci USA 1993;90:6961-5.

4 Tomita M, Itoh H, Ishikawa N, Higa N, Ide H, Murakumo Y, et al. Molecular cloning of mouse intestinal trefoil factor and its expression during goblet cell changes. Biochem $\mathcal{f}$ and its expression

5 Itoh H, Tomita $M$, Uchino $H$, Kobayashi T, Kataoka H, Sekiya $\mathrm{R}$, et al. cDNA cloning of rat pS2 peptide and expression of trefoil peptides in acetic acid-induced colitis. Biochem F 1996;318:939-44.

6 Mashimo H, Wu DC, Podolsky DK, Fishman MC. Impaired defense of intestinal mucosa in mice lackin intestinal trefoil factor. Science 1996;274:262-5.

7 Dignass A, Lynch-Devaney $K$, Kindon $H$, Thim L, Podolsky DK. Trefoil peptides promote epithelial migration through a transforming growth factor $\beta$-independent pathway. $\mathcal{F}$ Clin Invest 1994;94:376-83.

8 Henry JA, Bennett MK, Piggott NH, Levett DL, May FEB, Westley BR. Expression of the pNR-2/pS2 protein in diverse human epithelial tumours. $\mathrm{Br} \mathcal{F}$ Cancer 1991;64: diverse h

9 Taupin D, Ooi K, Yeomans N, Giraud A. Conserved expression of intestinal trefoil factor in the human colonic adenoma-carcinoma sequence. Lab Invest 1996;75:25-32.

10 Kindon H, Pothoulakis C, Thim L, Lynch-Devaney K Podolsky DK. Trefoil peptide protection of intestinal epithelial barrier function: cooperative interaction with mucin glycoprotein. Gastroenterology 1995;109:516-23. 